\title{
Preface: hydrogeoecology, the interdisciplinary study of groundwater dependent ecosystems
}

\author{
Peter J. Hancock • Randall J. Hunt • \\ Andrew J. Boulton
}

Keywords Ecology · Collaborative research . Groundwater/surface-water relations · Wetlands . Microbial processes

\begin{abstract}
Although we are still developing our understanding, there is increasing recognition that groundwater is essential to many ecological communities. Groundwater is a connector, not just in the aquifer itself, but within, across, and between surface waters and many terrestrial ecosystems. Where the water table intersects or comes close to the land surface, contributions of water and nutrients to plant roots and aquatic ecosystems can be critical to their persistence. Consider that precipitation is the dominant source of water in nearly all wetland systems, yet the influence of the lesser groundwater flow component can be sufficient from an ecological perspective to yield an entire new type of wetland, the fen. Influxes of groundwater to lakes, rivers, and wetlands can change whole-system physico-chemical properties such as temperature and salinity, while also providing more subtle influences on microenvironments and their ecological processes. Infiltration of water from surface aquatic ecosystems and rainfall can have an equally significant effect on aquifer ecology, especially on microbes and subsurface invertebrates. Whether water is flowing into or out of an aquifer, or is moving from one part to another, it is the extent and intensity of connectivity that often determines its importance to
\end{abstract}

Received: 11 November 2008 / Accepted: 17 November 2008 Published online: 20 December 2008

(C) Springer-Verlag 2008

P. J. Hancock $(\bowtie) \cdot$ A. J. Boulton

Ecosystem Management,

University of New England, Armidale, New South Wales, Australia, 2351

e-mail: phancoc2@une.edu.au

R. J. Hunt

US Geological Survey, Wisconsin Water Science Center, 8505 Research Way, Middleton, WI , 53362, USA ecosystems. Moreover, the same location in space can have all three types of flows at different periods of time. Surface ecological processes (such as evapotranspiration) can significantly impact hydrological responses and related hydrochemical function. Thus, the relation of groundwater hydrology to patterns and processes in ecology is a 'two-way street' where understanding the feedback of one to the other serves as a powerful lens through which to evaluate and explain the functioning of natural ecosystems.

The recognition of the significance and power of this tandem has not always been followed with effective interdisciplinary science. The ecological, hydrological, and physico-chemical links between groundwater, surface waters and associated ecosystems are seldom fully understood even though true characterization and wise management will require a multidisciplinary approach. This means biologists need to understand the importance of magnitude and timing of groundwater flows for their system, which requires the skills of hydrogeologists to achieve. Hydrogeologists, in turn, must understand how and why groundwater influences ecological processes so that their expertise is brought to bear at a scale commensurate to the ecological research question. This issue is not unlike the conversation between the hydrogeologist and the water engineer: although precisely defining the range of properties of "sand" can be quite labor-intensive, if the problem is broken down to a threshold of "Do I buy a $5-\mathrm{cm}$ or $10-\mathrm{cm}$ pipe for my pump?", it becomes more tractable. Thus, learning about ecological thresholds and tipping points for the question at hand can help ensure that the interdisciplinary work plan does not become overwhelming and is tackled efficiently. Execution of this interdisciplinary science must not occur in a vacuum: resource managers need to also understand the links between groundwater and terrestrial/subterranean ecosystems so that they can manage natural systems holistically, and have a complete evaluation of the threats and opportunities. Only then can they truly ensure the long-term sustainability of the resource and its ecosystem goods and services. 
One major purpose of this issue of Hydrogeology Journal (HJ) is to present examples that illustrate the current state and breadth of studies concerned with 'hydrogeoecology', a term used here to highlight studies focused on groundwater-ecology interaction. Similar to 'hydrogeology' residing within the larger study of 'hydrology', hydrogeoecology can be thought of as a subset within the broader field of 'hydroecology', the study of interactions between the hydrology of all water bodies and their ecological components. Our hope is that we will raise awareness among hydrogeologists of the importance of groundwater to a range of ecosystem-related questions, and to promote more effective consideration of the ecological consequences of hydrogeological decisions. In selecting the papers for the issue, we also sought to enhance understanding of hydrogeology amongst biologists as this discipline provides the template, or abiotic "box", within which ecological processes play out. One difficulty is that the groundwater-ecology links can be wide-ranging, including such well-recognized areas as water-plant interactions or groundwater-temperature-trout relations, but also less well-known areas such as microbial community characterization at the periphery of a contaminant plume. Thus, this issue of HJ is also intended to highlight the diverse ecosystems that depend on groundwater, include systems from around the world, and provide contemporary examples of interdisciplinary collaborations. Often, the degree of the collaboration is less than ideal "hydroecology" in that coverage of both disciplines is unequal, which underscores the difficulty of the endeavour as well as the infancy of this type of collaboration. It is difficult to know where to go when the path is uncharted.

This issue echoes earlier calls for hydrogeologists, biologists and researchers in other disciplines to work together (Hancock et al. 2005, Hunt and Wilcox 2003). Appeals for collaboration are made in nearly all of the papers in this issue, but are most overtly stated by Humphreys. In this opening paper, Humphreys reiterates the concepts of aquifers as a place to live and of groundwater as a means of delivering oxygen and food to microbial and invertebrate communities. He also provides an excellent summary of the value of the "twoway street" by reviewing both how an understanding of hydrogeology can help biologists and how biological processes are critical in maintaining water quality and can be of practical use to hydrogeologists and managers. Steube et al. continue the theme of using ecological knowledge as a tool for management in their paper calling for groundwater assessment to incorporate biological criteria as well as physico-chemical and hydrological variables. They discuss the promising potential of microbes as biological indicators, providing examples from their research near Cologne in north-western Germany. In a similar vein, Pronk et al. demonstrate how bacteria have been used to indicate temporal variability in the links between a swallow hole and a spring in the Swiss Alps. These researchers employed bacterial genetic fingerprint techniques to show how contributions of allochthonous bacteria entering springs through the aquifer vary with the strength of recharge at the swallow hole. Sinreich et al. used solute and particle tracers to improve understanding of mass transport rates in an epikarstic system. Surface-water intrusion was also demonstrated ecologically by Bork et al. using the recently developed GW-Fauna-Index (Hahn 2006; GW being groundwater) to investigate surface water inputs into an alluvial aquifer in South Korea.

The classification of groundwater systems so they can be better incorporated into management frameworks is essential for sustainable management. Although there are regional frameworks already in existence (often based on aquifers grouped by jurisdictional boundaries), they seldom consider ecologically relevant variables. Hahn calls for the ecological classification of aquifer habitats, urging the adoption of a 'groundwater habitat typology' at multiple scales across the landscape. This typology considers aquifer type, biogeography, and hydrological exchange as key drivers of ecological distribution in aquifers and Hahn argues that these variables should be considered in the sustainable management of groundwater. Adding further to this, Springer and Stevens propose a classification system for springs, identifying and describing 12 spheres of discharge by variations in hydrogeology and microhabitat. These authors discuss threats to spring ecosystems and recommend that efforts concentrate on understanding and conserving the most threatened spring types. Berglund et al. illustrate how high-profile societal decisions such as where to site a nuclear waste repository require hydrogeological and ecological input, while Gasca and Ross illustrates how various levels of scientific inquiry can be brought to bear to answer societal questions regarding management of water resources near a valued ecosystem.

As mentioned earlier, groundwater-related processes are critical to many surface-water ecosystems. Vincenzi et al. show how a large-scale hydrologic disturbance related to tunnelling can have large-scale repercussions on stream systems. The exchange of water by the hyporheic zone, as demonstrated by Claret and Boulton, occurs at a range of scales with ecological effects on surface streams and the underlying groundwater. Further examples of groundwater exchange influencing surface ecology are provided by Malcolm et al. and Olsen and Young, examining physico-chemical aspects of groundwater exchange important to salmonid fish ecology. Malcolm et al. show how dissolved oxygen varies over very fine spatial scales in groundwater exchange zones, and demonstrate that studies need to be conducted at a scale relevant to the ecological process of interest. Olsen and Young assess whether areas of upwelling cool groundwater provide thermal refugia for brown trout during summer. Harvey and McCormick examine the impacts of declining groundwater quality and increased groundwater-surface water interactions on ecological communities in the Everglades, Florida, USA.

Surface vegetation too is affected by groundwater processes; van der Kamp and Hayashi provide a 
conceptual framework for the hydrogeologic-plant community association for the Prairie Pothole region of North America. Skalbeck et al. show that the rate of groundwater loss from a wetland system can be as important a determinant of plant community and wetland type as the more well-recognized groundwater inflow into the wetland root zone. Loheide et al demonstrate how changes in vegetation communities in Californian (USA) wet meadows are influenced by the spatial variation in shallow water-table depth. Finally, the feedback mechanism of the ecology on the hydrologic system is explored. In waterlimited environments, water tables can be extremely deep yet aquifers are the only reliable source of water, forcing some trees to extend their roots tens of meters. Lubczynski reviews the physiology and hydrogeological role of trees. $\mathrm{He}$ argues that groundwater use by trees is often considerable and should not be ignored by hydrogeologists during modelling, especially in water-limited environments.

\section{Conclusions}

This issue of HJ provides a current picture of how hydrogeoecology has been performed during a period before dominant textbooks or widely accepted common methodologies have been identified. Although notable for its breadth and innovation, four primary elements can be distilled from this work to present a foundation for future hydrogeoecological endeavours.

For collaborative research to improve our understanding of links between groundwater and ecosystems, it needs to focus on spatial and temporal scales that are relevant to both the hydrogeological and the ecological process being studied. This is important to note because historically hydrogeological studies often were performed on the aquifer or site scale, thus using approaches and generating data too broad for understanding many ecological processes.

There is a need to translate each science into terms and metrics that have currency in the other. Ecologists may resist having their science being held to the precision that hydrogeologists routinely report, yet are comfortable focusing on thresholds and tipping points for their ecosystem. In an obvious example, a stream drying up is a very different ecological system than a perennial stream with various degrees of low flows, and characterization of either is a realistic expectation of hydrogeological investigation.

There is a need to recognize that the skill set for true interdisciplinary 'hydrogeoecology' spans more than any one person can hope to achieve in a lifetime of learning. Inevitably, there needs to be research that uses teams of scientists, and work plans and budgets should reflect this reality.

Ultimately, much of the work done by researchers must meet the needs of resource managers and society. Hydrogeoecology epitomizes the holistic approach required to truly meet these needs. It is our charge to develop the discipline to realize this result, and we urge researchers and managers to work together to develop relevant, innovative and tractable research questions and directions.

In the end, this issue lays out a promise for a societally relevant and necessary science. We believe that, in many ways, the road ahead for attaining widespread and thoroughly integrated hydrogeoecology is longer than the road travelled thus far. However, like all worthy journeys, all steps along the way are necessary to reach the end. We hope this issue is a productive step, and promotes some further partnerships of hydrogeologists and ecologists in the new field of hydrogeoecology.

\section{References}

Hahn HJ (2006) The GW-Fauna-Index: a first approach to a quantitative ecological assessment of groundwater habitats. Limnologica 36:119-137

Hancock PJ, Boulton AJ, Humphreys WF (2005) Aquifers and hyporheic zones: towards an ecological understanding of groundwater. Hydrogeol J 13:98-111

Hunt RJ, Wilcox DA (2003) Ecohydrology: why hydrologists should care. Ground Water 41:289 